\title{
Observations of seismic T-waves along the NE Brazil coastline
}

\author{
${ }^{123}$ Guilherme W. S. de Melo, ${ }^{4}$ Robert P. Dziak, ${ }^{1}$ Aderson F. do Nascimento \\ 1-Departamento de Geofísica - Universidade Federal do Rio Grande do Norte - UFRN - Brazil \\ 2-Department of Geological Sciences - San Diego State University - SDSU - USA \\ 3-Scripps Institution of Oceanography - University of California San Diego, UCSD - USA \\ 4-Pacific Marine Environmental Laboratory - National Oceanic and Atmospheric Administration - NOAA - USA \\ gsampaiodemelo@ucsd.edu
}

Copyright 2021, SBGf - Sociedade Brasileira de Geofísica.

This paper was prepared for presentation during the 17th International Congress of the Brazilian Geophysical Society held in Rio de Janeiro, Brazil, 8-11 November 2021 (Online Event). Contents of this paper were reviewed by the Technical Committee of the $17^{\text {th }}$ International Congress of the Brazilian Geophysical Society and do not necessarily represent any position of the SBGf, its officers or members. Electronic reproduction or storage of any part of this paper for commercial purposes without the written consent of the Brazilian Geophysical Society is prohibited.

Moderate magnitude $\geq 4.0 \mathrm{Mw}$ earthquakes, located on the edge of tectonic plates in the equatorial Atlantic ocean, are commonly recorded by global seismographic stations. The seismic waves generated from these events are refracted through the seafloor near the epicenter, in which part of the energy propagates into the oceanic water layer, and converts to acoustic waves called $T$ (tertiary) waves. $T$ waves propagate within the SOFAR (Sound Fixing and Ranging) channel, a low sound-speed zone which forms a waveguide and allows propagation over long distances (more than 1,000 km) with low attenuation. When T waves reach the coast (e.g. islands or continental margins), the $\mathrm{T}$ waves convert back to seismic propagation. Previous authors have reported that the sediments along the continental shelves of Australia and the United States play an important role in the acoustic-seismic energy transfer. However, this conversion process, and the changing of the acoustic energy to seismic $T$ waves in the solid Earth, are poorly known in the equatorial Atlantic region. There are only two examples in the literature of $\mathrm{T}$ wave studies at seismic stations located on islands of the North Atlantic. To better understand the propagation of $\mathrm{T}$ waves in the equatorial Atlantic, we present the analysis of five $\mathrm{T}$ wave generating earthquakes with moment magnitudes $\geq 5.7$ from the Romanche Transform Fault, as well as two events ( $\mathrm{Mw}$ 25.8) from the Chain Transform Fault. Our objective is to describe the behavior of $T$ wave propagation by using data from 25 broadband seismographic stations of the Brazilian Seismographic Network. The source events were chosen from the Global Centroid Moment Tensor (GCMT) catalog. The Romanche Transform earthquakes exhibited seismic T-wave amplitudes with azimuthal distributions of $\sim 220^{\circ}$, with the southernmost stations at $\sim 270^{\circ}$ azimuth. The maximum amplitudes are at $\sim 240-250^{\circ}$ azimuth, with amplitudes decaying at both northward and southward stations. We did not identify any direct correlation in amplitude correlation with epicentral distance or length of the continental travel path. Similarly, the Chain Transform events shown a coastline distribution in range between $230^{\circ}$ and $265^{\circ}$ azimuth, with the highest seismic T-wave amplitudes at stations of $\sim 255^{\circ}$ azimuth. Finally, the preliminary results presented here indicate there is a correlation between the maximum seismic T-wave amplitude and azimuth from earthquake source to seismic receiver along the Brazilian coast. Our interpretation is that the radiation pattern of the seismic source influences the T-wave amplitudes recorded along and inland of the Brazilian coast. 